\title{
Psychological capital development effectiveness of face-to-face, online, and Micro-learning interventions
}

\author{
Justin W. Carter ${ }^{1}$ (D) $\cdot$ Carolyn Youssef-Morgan² ${ }^{2}$
}

Received: 26 May 2021 / Accepted: 17 November 2021 / Published online: 19 January 2022

(c) The Author(s), under exclusive licence to Springer Science+Business Media, LLC, part of Springer Nature 2022

\begin{abstract}
There is growing empirical support for the benefits of developing psychological capital (PsyCap), and the effectiveness of PsyCap interventions (PCIs) in the workplace. However, to-date, PCI delivery modes have not been compared. The first study in this article compares a face-to-face to an online PCI. The second study compares an online PCI to a micro-learning PCI utilizing a mobile application. Results from 228 participants assessed three times (before, immediately after, and six weeks after PCI completion) support the effectiveness and comparability of the three delivery modes, but also highlight notable advantages for online and micro-learning.
\end{abstract}

Keywords Psychological capital $\cdot$ Hope $\cdot$ Optimism $\cdot$ Resilience $\cdot$ Self-efficacy · Online learning $\cdot$ Microlearning

The unprecedented measures taken during the Covid-19 pandemic have left permanent marks on life and business. As many organizations (e.g., businesses, schools, dining, entertainment) have been forced to switch to remote, minimal contact, or virtual settings, there is a renewed focus and need for online learning. Additionally, social distancing and remote working during the pandemic has been shown to result in a host of mental health problems, including increased feelings of loneliness, helplessness, fear, and anxiety; decreased productivity; and a diminished sense of control in general. These adverse effects were evident, even among employees of multinational technology companies that specialize in internet-related services, such as Google, Amazon, and Facebook (Robinson, 2020).

As a result, there is growing interest in positivity and wellbeing in general, and more specifically positive psychological interventions that can facilitate coping and promote wellbeing (Bolier et al., 2013; Seligman et al., 2005; Sin \& Lyubomirsky, 2009). These positive interventions can help supplement other professional mental

Justin W. Carter

jwcarter@una.edu

1 University of North Alabama, 1 Harrison Plaza, Florence, AL 35632, USA

2 Bellevue University, 1000 Galvin Rd S, Bellevue, NE 68005, USA 
health services, or fill gaps where these services are unavailable. Moreover, they can have wider reach because they can be successfully implemented in everyday contexts (e.g., schools, workplaces). Importantly, positive interventions are accessible to individuals who do not necessarily meet the criteria for a mental health diagnosis, but for those who do, positive interventions do not have the same stigma as pursuing treatment for mental illness, which makes them attractive to a wider population base (Broad \& Luthans, 2020; Luthans \& Broad, in press).

Positive psychology has been instrumental in promoting the study and application of positivity in various life domains. Positive organizational behavior, a more specific application of positive psychology, focuses on the study and application of four specific positive psychological resources that can be measured and developed to promote performance and wellbeing (Luthans, 2002a). Hope, efficacy, resilience, and optimism have been integrated into a multidimensional construct psychological capital (PsyCap), which is defined as "an individual's positive psychological state of development that is characterized by: (1) having confidence (self-efficacy) to take on and put in the necessary effort to succeed at challenging tasks; (2) making a positive attribution (optimism) about succeeding now and in the future; (3) persevering toward goals and, when necessary, redirecting paths to goals (hope) in order to succeed; and (4) when beset by problems and adversity, sustaining and bouncing back and even beyond (resilience) to attain success" (Luthans et al., 2015, p.2).

Interventions to increase PsyCap have been successfully administered face-toface (Dello Russo \& Stoykova, 2015; Demerouti et al., 2011; Ertosun et al., 2015; Luthans et al., 2006; Luthans et al., 2010; Luthans et al., 2014; Stratman \& YoussefMorgan, 2019) and online (Luthans et al., 2008). However, no study to-date has compared the effectiveness of these two approaches. Moreover, online learning is not a single method. There are numerous approaches and technologies available for online learning, some of which have been implemented in the context of positive psychology (Baños et al., 2017). However, research that directly compares the effectiveness of these alternative approaches and technologies is lacking in general, and particularly in the context of PsyCap development.

This study endeavors to fill these gaps, by comparing the effectiveness of faceto-face and two types of online PsyCap development interventions. The first online PsyCap development intervention follows the most common approach to online learning, which is delivering identical content to face-to-face learning on an online platform. The second PsyCap development intervention follows a "micro-learning" approach, in which content is delivered gradually in shorter modules over a sixweek period, allowing participants more time to cognitively process and apply that content in-between modules.

\section{Psychological capital}

In a special edition of the American Psychologist, Seligman and Csikszentmihalyi (2000) highlight the need for research that focuses on human excellence and positivity, rather than just mental illness and other deficits. Their call to action spearheaded the field of study coined "positive psychology" which quickly found its way 
into the workplace (Cameron et al., 2003) and many other life domains. Positive organizational behavior focuses on specific positive psychological resources that can be measured, developed, and managed, with evidence for impact on performance and wellbeing (Luthans \& Youssef, 2007). Grounded in positive psychology and evidence-based management, PsyCap is a multidimensional higher order construct that synergistically includes four resources: hope, efficacy, resilience, and optimism (Luthans et al., 2007).

Hope Hope is defined as "a positive motivational state that is based on an interactively derived sense of successful (1) agency (goal-directed energy) and (2) pathways (planning to meet goals)" (Snyder et al., 1991, p. 287). Hope is a positive state that exhibits agency (willpower) and pathways (waypower) in the pursuit of goals (Snyder, 1994). Agency is the belief that one can influence action (Bandura, 1998). Pathways involve the ability to generate multiple options and ways to overcome obstacles when pursuing a goal. Individuals with hope view goals through the lens of success, which gives them an "empowering way of thinking" (Snyder, 1994, p.2).

Self-efficacy Self-efficacy is defined as “one's conviction (or confidence) about his or her ability to mobilize the motivation, cognitive resources, and courses of action needed to successfully execute a specific task within a given context" (Stajkovic \& Luthans, 1998, p. 66). Self-efficacy is considered "the foundation of action" (Bandura, 1998, p.52). It requires observation and self-reflection by the individual (Bandura, 1997). It is central to social cognitive theory, which argues that an individual's development is influenced by both social learning and internal agency (Bandura, 2001). Therefore, it is the ability to self-reflect on cause and effect relationships that strengthens self-efficacy, ultimately promoting self-directed actions and the pursuit of challenging goals (Bandura, 1997; Bandura, 1998; Bandura, 2001).

Resilience Luthans (2002b, p.702) defines resilience as "the capacity to rebound or bounce back from adversity, conflict, failure, or even positive events, progress, and increased responsibility." Resilience is the ability to move on from a negative experience in a positive way (Tugade et al., 2004). This implies that resilience is not simply bouncing back, but also reacting and adapting effectively to both negative and positive (but possibly challenging or overwhelming) events, learning from and growing through them. In other words, resilience involves not only going back to 'normal' after a challenge or a setback, but reaching new heights of strength and growth. Resilience is influenced by the assessment of risks, assets, and adaptational processes (Masten, 2001).

Optimism Tiger (1979) defines optimism as a "mood or attitude associated with an expectation about the social or material future - one which the evaluator regards as socially desirable, to his advantage, or for his please" (p.18). Optimism is a learned thought process of explaining the causes of events (Seligman, 1998) where positive events are attributed to personal, permanent, and pervasive causes, and negative events to external, temporary, and situational causes (Buchanan \& Seligman, 
1995). Optimistic individuals link negative events to external sources and positive events to internal sources (Seligman, 1998), allowing them to take credit for positive events, and distance themselves from the harmful effects of negative events, especially when they cannot be changed or altered (Luthans \& Youssef, 2007). However, this view is grounded in reality (Schneider, 2001). Therefore, optimism is a learned realistic positive assessment of causes when an event takes place. In addition to this attributional perspective, optimism is also an overall positive outlook that involves positive future expectancies in general. In other words, optimists generally expect good things to happen (Mens et al., 2016).

Psychological capital as a higher-order construct PsyCap is a multidimensional higher order construct with interrelated dimensions. Although each of the four resources has been independently theorized, measured, and empirically supported (Bandura, 1997; Masten, 2001; Seligman, 1998; Snyder, 2000), their convergent and discriminant validity have been established (Bryant \& Cvengros, 2004; Carifio \& Rhodes, 2002; Magaletta \& Oliver, 1999). Luthans and Youssef (2007) argue, and Luthans et al. (2007) empirically show that the four psychological resources work together and have more predictive power than any of the individual resources. Luthans et al. (2007) describe the commonality between hope, self-efficacy, resilience, and optimism as a "positive appraisal of circumstances and probability for success based on motivated effort and perseverance" (p. 550). Therefore, each resource contributes to PsyCap's internalized agency, positive expectancies, motivation, and perseverance. Stajkovic (2006) argues that hope, self-efficacy, resilience, and optimism share a common foundation referred to as "core confidence" (p.1209).

\section{Psychological capital and positive outcomes}

PsyCap is positively related to multiple desirable attitudes, behaviors, and performance, and negatively related to undesirable outcomes (Avey et al., 2011; Luthans et al., 2007). For example, PsyCap is negatively related to stress and anxiety (Avey et al., 2009), unsafe workplace behaviors (Stratman \& Youssef-Morgan, 2019), cynicism, intentions to quit, and counterproductive work behaviors (Avey, Luthans, \& Youssef, 2010a). Conversely, PsyCap has been found to predict positive attitudes such as job satisfaction (Luthans et al., 2007), organizational citizenship behaviors (Avey et al., 2010b, b), general wellbeing and satisfaction with various life domains (Avey et al., 2010b, b; Luthans et al., 2013).

Performance is the most researched work-related outcome for PsyCap (Avey et al., 2011), and PsyCap has been shown to be a better predictor of work performance than any of the four sub-constructs individually (Luthans et al., 2007). Longitudinally, changes in PsyCap over time predict both performance ratings (Carter \& Youssef-Morgan, 2019) and sales performance (Peterson et al., 2011), and both leader and follower PsyCap interact to positively predict performance (Walumbwa et al., 2010). A meta-analysis using 51 independent samples found a significant positive relationship between PsyCap and self-reported performance measures, performance evaluations, and objective performance measures, with no significant 
differences between the different types (Avey et al., 2011). Additionally, PsyCap was found to have a positive ROI for organizations (Youssef \& Luthans, 2007). Beyond work performance, PsyCap has also been shown to predict academic performance (Martínez et al., 2019), as well as health and relationships (Luthans et al., 2013). These findings highlight the importance of developing PsyCap.

\section{Psychological capital development interventions}

Luthans (2002a) argues that positive organizational behavior resources must be open to development. The requirement of being open to development is an important distinction from many other positive psychology concepts. Luthans and Youssef (2007) place PsyCap in an intermediate "state-like" position on the trait-state continuum. Traits and trait-like constructs (e.g., intelligence, personality) are stable and difficult to change, while states (e.g. emotions) are volatile and momentary. On the other hand, state-like resources such as PsyCap can be developed through short interventions, with reasonably sustainable benefits (Luthans \& Youssef, 2007; Luthans \& Youssef-Morgan, 2017). For example, Dello Russo and Stoykova (2015) show the durability of PsyCap development effects over time, which supports its statelike nature. This notion is also supported by Corbu et al. (2021) recent study, which shows PsyCap increased significantly directly after a positive micro-coaching intervention, and the increase was sustained four months after.

There is growing evidence for the effectiveness of PsyCap development interventions (Dello Russo \& Stoykova, 2015; Luthans et al., 2008; Luthans et al., 2010; Luthans et al., 2014; Stratman \& Youssef-Morgan, 2019). The development of PsyCap does not require a large investment of time or resources and can be accomplished in a few hours (Luthans et al., 2006), and these interventions can have a positive return on investment if done thoughtfully (Youssef-Morgan, 2014).

The synergistic nature of the four positive psychological resources that constitute PsyCap led Luthans et al. (2006) to develop a prototype for psychological capital interventions (PCIs) that aim to develop these resources together, rather than one at a time. This "shotgun" approach has been found to be more effective in positive psychological interventions in general (Seligman et al., 2005; Sin \& Lyubomirsky, 2009). In a typical PCI, participants set clearly defined goals and subgoals. The goals should be measurable, internalized, challenging, and framed as approach-oriented, rather than avoidance-oriented. Participants work through a process of identifying multiple pathways to accomplish their goals, addressing potential obstacles, listing available resources, and mentally rehearsing their journey of goal pursuit. These exercises build the participant's hope, self-efficacy, resilience and optimism.

Although the original PCI developed by Luthans et al. (2006) was a face-to-face intervention, additional studies show that online learning can also be effective in developing participants' PsyCap (Luthans et al., 2008). The development of PsyCap online through remote and technologically-enabled learning tools is particularly appealing in the current environment due to the shift of work, education, services, and many other areas of life to virtual settings. This trend has been on the rise prior to COVID-19, but was accelerated by the pandemic. Moreover, successful 
implementation and experience gained through the pandemic are likely to make this trend persist in the long term. Broad and Luthans (2020) argue that developing PsyCap remotely and using new technologies is a necessity in the emerging "fourth industrial revolution" that has been accelerated by COVID-19, but more importantly by an increasingly Volatile, Uncertain, Complex, and Ámbiguous (VUCA) environment. In this environment, there is an immense need for positivity in order to promote mental health and overcome the harmful side effects of isolation and rapid change. Simultaneously, there are unprecedented opportunities to capitalize on technology and deliver evidence-based positive interventions to all types of audiences to promote wellbeing and performance. These opportunities go beyond just online delivery, which has become commonplace in many educational settings. For these reasons, this study attempts to compare the effectiveness of two of these options, namely online versus microlearning, in comparison to traditional face-toface learning.

\section{Online and face-to-face learning}

Over a decade ago, Lam (2009) asserted that face-to-face instruction made up the vast majority of delivery methods used. Online instruction attempts to mirror faceto-face delivery, but take place electronically through online platforms (Sampson, 2003), while face-to-face instruction takes place in person. Although face-to-face instruction has dominated over the last decade, web-based instruction has quickly grown in popularity because of its flexibility, cost effectiveness, and potential to reach a larger audience (Greenhalgh, 2001), and has grown exponentially due to COVID-19 (Lieberman, 2020).

From its early beginnings, online learning has generated much debate around its effectiveness (Stromso \& Braten, 2010; Robinson \& Hullinger, 2008), especially in comparison to face-to-face learning. Russell's (1999) No Significant Difference Phenomenon utilized evidence to-date to build compelling arguments and settle that debate. In support of online learning, and to refute arguments against its effectiveness, Russell (1999) provides an in-depth review of numerous studies that compares the two approaches from a broad spectrum of subjects, asserting that there is no significant difference between them.

More recent studies have also concluded that there is no significant difference between online and face-to-face instruction for learning languages (Ghonsooly \& Seyyedrezaie, 2014), evidence-based medicine (Davis et al., 2008) fall prevention practices (Maloney et al., 2012), and evaluation methodologies (Francescato et al., 2006).

However, there are those that have questioned the validity of the evidence for the equivalence of online and face-to-face learning. Merisotis and Phipps (1999) pointed out that the majority of the studies used in Russell's (1999) research failed to control for extraneous variables or use valid tools to measure outcomes. There are also plenty of studies with conflicting conclusions. Summers et al. (2005) compared the grades for students in an online and face-to-face introductory statistics class and found no significant difference in performance, but Wakil et al. (2019) more recently 
found a highly significant difference in grades between online and face-to-face students in a tenth grade statistics course. Similarly, Motiwalla and Tello (2000) posited that online students are more satisfied with their courses, but Johnson et al. (2000) found that face-to-face students had more positive perceptions about their instructor and overall course quality.

Sanders (2006) argues that online platforms can't replicate the serendipitous moments of learning that happen naturally with the physical presence of an instructor and peers. Jenkins (2009) adds that online learning can create a "participation gap" for certain populations that lack the resources needed. Patterson and McFadden (2009) found that online programs had six to seven times higher dropout rates when compared to face-to-face programs. Conversely, Kearns et al. (2004) found that online nursing students perform better when compared to face-to-face students.

More specific to psychological interventions, online programs have been effective in developing stress management techniques (Zetterqvist et al., 2003) and improving cognitive wellbeing (Mitchell et al., 2009), supporting the argument that online learning can go beyond basic skills and influence mental health. A recent meta-analysis by Carlbring et al. (2018) shows that online cognitive behavior therapy is just as effective as face-to-face cognitive behavior therapy. Similarly, a meta-analysis of 92 internet-based psychotherapeutic interventions showed comparable effectiveness to face-to-face therapy (Barak et al., 2008).

Even more specific to positive psychological interventions, online learning has been shown to be effective in inducing positive emotions and reinforcing psychological resources (Baños et al., 2014) and promoting self-compassion and optimism (Shapira and Mongrain (2010). Strengths-based positive interventions have also been shown to be effective in enhancing wellbeing and alleviating depression (Gander et al., 2013; Proyer et al., 2014). Considering the balance of this evidence, we anticipate face-to-face and online PsyCap development interventions to be comparable in effectiveness. In other words, we expect no significant difference between face-to-face and online PCIs.

Hypothesis 1. There is no significant difference between face-to-face and online PCI.

\section{Micro-learning}

Despite the rapid growth in online learning, the methods used for online learning have remained relatively static (Buchem \& Hamelmann, 2010). As a result, online programs have struggled to adapt to the demands of today's adult learners that require short learning opportunities (Gassler et al., 2004) preferably on mobile devices (Agah \& Ayse, 2011). While typical online learning focuses on replicating face-to-face instruction using an online platform, micro-learning takes complex topics and breaks them down into smaller learning modules, spaced out over time. Although there is no unified definition of micro-learning at this time (Mohammed et al., 2018), the basic pedagogy centers on learning in short segments (Major \& Calandrino, 2018). This approach is compatible with today's communication and 
information delivery. The use of mobile technology has provided a cost-effective way to space out instruction, providing the learner time to reflect on the material before moving to the next topic. Mobile devices have the additional benefit of being always available, personalized to the user, and adaptable to their owner's schedule and location (Wong, 2012).

Although the concept of micro-learning is relatively new, breaking down complex information into smaller digestible chunks can be traced back to distributed learning (Youtz, 1941) and spaced learning (Ebbinghaus, 1964). The distributed learning effect refers to the increase in retention when information is presented over multiple small sessions distributed across time (Litman \& Davachi, 2008). Bruck et al. (2012) point out that a key characteristic of micro-learning is the time required to complete each assignment. Goodyear (2006) argues that time is oddly underexamined in the online learning literature. Typically, micro-activities are between two to ten minutes each (Cole \& Torgerson, 2017). When compared to mass learning sessions conducted at one time, distributed learning has been shown to provide a mnemonic advantage in the learning process (Cepeda et al., 2006; Janiszewski et al., 2003). Specifically, it increases memory consolidation (Litman \& Davachi, 2008). This notion is supported by cognition theories, which highlight limitations on the amount of information that can be processed in short-term memory at any given time (Cowan, 2001).

Similarly, the spacing effect is well established in memory literature. Spaced repetitions have been shown to produce superior interpolation and extrapolation performance (Cepeda et al., 2006). A meta-analysis performed by Donovan and Radosevich (1999) supports that information presented over spaced periods has a clear advantage in the amount of learning that occurs when compared to material presented in a single session. Additionally, participants in spaced practice conditions perform significantly higher when compared to those in mass practice conditions (Donovan \& Radosevich, 1999). Although the majority of research on spaced methods focused on basic skill development, Cole and Torgerson (2017) argue that this approach can also be used for more complex topics. Their assertion is supported in complex domains such as medical training (Moulton et al., 2006), statistics (Smith \& Rothkopf, 1984), biology (Reynolds \& Glaser, 1964), sales training (Kauffeld \& Lehmann-Willenbrock, 2010), and artistic styles (Kornell \& Bjork, 2008).

Micro-learning presents information in the most common way people learn today. Mobile devices are the fastest growing technology worldwide. In 2020 there are 5.24 billion unique mobile device users around the world, and this number is expected to increase to 7.33 billion in 2023 (Turner, 2020). Rapid adoption of smartphones, along with online platforms such as Twitter and Facebook, have opened up new pathways of communication using condensed content. At the same time student attention spans have continued to decrease over the last thirteen years (Mohammed et al., 2018). Micro-learning embraces these changes by taking condensed shortform information focused on a singular topic, referred to as micro-content, and producing micro-activities through mobile applications (Skalka \& Drlík, 2018), with the purpose of breaking down complex information into more manageable chunks.

The literature on the effectiveness of micro-learning is limited. However, Mohammed et al. (2018) found that primary school students perform $18 \%$ better 
using micro-learning when compared to students taught under the traditional method. Similarly, international property law students at Dresden University of Technology in Germany performed $20 \%$ better on assessment questions and $8 \%$ better on computational questions after micro-learning (Kapp et al., 2015). Additionally, micro-learning has been successfully implemented in workplace learning initiatives (Werkle et al., 2015), including patient safety training (Gross et al., 2019). Given its cost-effective nature and potential, it is not surprising that 93\% of organizations plan to increase the use of micro-learning (Cole \& Torgerson, 2017). Therefore, this study aims to compare the effectiveness of online and micro-learning in the context of PsyCap development. Based on earlier arguments, we expect both types of learning to be comparable. In other words, we expect no significant difference between online and micro-learning PCIs.

Hypothesis 2. There is no significant difference between online and microlearning PCI.

\section{Methods}

\subsection{Sample, design and procedures}

Participants were employees at a large, well-established U.S.-based construction materials supplier. The company has over 6500 employees in more than 400 facilities in 21 states. The training was conducted in two waves, which constituted the samples for Study 1 and Study 2, respectively.

Study 1 sample The sample for this study included 118 participants. Average tenure was 5.17 years $(\mathrm{SD}=3.52$ years). Average years of education (high school $=13$ years) was 12.68 years $(S D=1.12$ years). The sample included $27 \%$ females and $48 \%$ minorities. Participants were randomly assigned to two groups. The first group $(\mathrm{N}=60)$ received a face-to-face PsyCap development intervention. The second group $(\mathrm{N}=58)$ received an online PsyCap development intervention. Participants completed assessments of their PsyCap and successful goal achievement before, immediately after, and six weeks after the intervention. Four participants in the first group, and three participants in the second group, did not complete the assessments six weeks after the intervention.

Study 2 sample The sample for this study included 110 participants. Average tenure was 4.94 years $(\mathrm{SD}=3.48$ years). Average years of education (high school $=13$ years) was 12.72 years $(S D=1.11$ years). The sample included $20 \%$ females and $48 \%$ minorities. Participants were randomly assigned to two groups. The first group $(\mathrm{N}=56)$ received a micro-learning PsyCap development intervention. The second group $(\mathrm{N}=54)$ received an online PsyCap development 
intervention. Five participants in the first group, and four participants in the second group, did not complete the assessments six weeks after the intervention.

\subsection{The PsyCap development interventions}

The PCI was designed in strict adherence to the guidelines provided in Luthans et al. (2006), Luthans et al. (2015), and Luthans and Youssef-Morgan (2017), and applied in all PsyCap development interventions to-date. Specifically, participants were first asked to identify a recent adverse situation they had experienced. This event was used as the foundation for the first two exercises focused on increasing the participants' ability to accurately frame events. Participants were then asked to make a list of their current goals, prioritize those goals, and select one to focus on for the remainder of the course. Using the participants' goals as the foundation, the remaining exercises focused on designing strategies to leverage resources, pinpointing potential pathways, and identifying obstacles. Each module introduced a new concept and allowed the participant to use what they had learned in guided exercises.

The content of the face-to-face, online, and micro-learning PCIs was identical. Participants completed the components sequentially. However, the face-to-face and online PCIs presented all the modules in one three-hour session. The micro-learning PCI presented one module each week. The face-to-face PCI was facilitated by an instructor in a classroom at the corporate office of the organization. The online PCI was hosted on the organization's learning management system. The micro-learning PCI was delivered using a mobile application.

\subsection{Variables and measures}

PsyCap was measured using the 24-item psychological capital questionnaire (PCQ24; Luthans et al., 2007). This measure includes six items measuring each of the PsyCap resources (hope, efficacy, resilience, and optimism). Cronbach's Alphas for this scale before, immediately after, and six weeks after the intervention were .895 , .911 , and .905 in Study 1; and .885, .931, and .926 in Study 2.

In addition to PsyCap, a single-item outcome variable, successful goal achievement, was assessed using the following question: "Up to today, how successful have you been in achieving the goals set during your performance dialogues?" This item was also rated on a six-point scale. This variable was also assessed immediately after, and six weeks after the intervention.

Confirmatory factor analysis was used to assess the measurement model. To maintain an acceptable sample-to-item ratio, content-based parceling (Landis et al., 2000) was used to reduce the number of PsyCap indicators. Specifically, the six items measuring each of the PsyCap resources were averaged, which resulted in four indicators for PsyCap. The measurement model showed excellent fit. Sample 1 fit indices were as follows: before intervention, $X^{2}(5)=3.640$, $\mathrm{p}=.602, X^{2} / \mathrm{df}=.728, \mathrm{CFI}=1.000, \mathrm{RMSEA}=.000$; immediately after intervention, $X^{2}(5)=1.430, \mathrm{p}=.921, X^{2} / \mathrm{df}=.286, \mathrm{CFI}=1.000, \mathrm{RMSEA}=.000 ;$ and six weeks 
after intervention, $X^{2}(5)=1.988, \mathrm{p}=.851, X^{2} / \mathrm{df}=.398, \mathrm{CFI}=1.000, \mathrm{RMSEA}=.000$. Sample 2 fit indices were as follows: immediately before intervention, $X^{2}(5)=5.328$, $\mathrm{p}=.377, X^{2} / \mathrm{df}=1.066, \mathrm{CFI}=.996, \mathrm{RMSEA}=.025$; immediately after intervention, $X^{2}(5)=6.517, \mathrm{p}=.259, X^{2} / \mathrm{df}=1.303, \mathrm{CFI}=.991, \mathrm{RMSEA}=.053$; and six weeks after intervention, $X^{2}(5)=8.060, \mathrm{p}=.153, X^{2} / \mathrm{df}=1.612, \mathrm{CFI}=.983, \mathrm{RMSEA}=.075$.

\section{Results}

\subsection{Descriptive statistics}

Means, standard deviations, and correlations among the study variables are presented in Table 1.

\subsection{Pre-intervention group equivalence}

Before examining the relative effectiveness of the PCIs in developing PsyCap and promoting successful goal achievement, it is important to ensure that random assignment yielded equivalent groups in both studies. There were no significant differences between the online and face-to-face groups in Study 1 with respect to preintervention PsyCap $[\mathrm{F}(1,116)=.343, \mathrm{p}=.559]$, pre-intervention successful goal achievement $[\mathrm{F}(1,116)=.122, \mathrm{p}=.727]$, tenure $[\mathrm{F}(1,116)=.720, \mathrm{p}=.398]$ education $[\mathrm{F}(1,97)=2.662, \mathrm{p}=.106]$, gender $\left[X^{2}(1)=.277, \mathrm{p}=.680\right]$, or race (minority vs. nonminority) $\left[X^{2}(1)=.296, \mathrm{p}=.713\right]$.

Similarly, there were no significant differences between the online and micro-learning groups in Study 2 with respect to pre-intervention PsyCap [F $(1,108)=1.425, \mathrm{p}=.235]$, pre-intervention successful goal achievement

Table 1 Descriptive Statistics and Correlations among the Study Variables

\begin{tabular}{|c|c|c|c|c|c|c|c|c|}
\hline & Mean & $S D$ & 1 & 2 & 3 & 4 & 5 & 6 \\
\hline \multicolumn{9}{|c|}{ Study $1(N=111)$} \\
\hline 1. PsyCap T1 & 4.69 & .490 & .895 & & & & & \\
\hline 2. PsyCap T2 & 4.89 & .446 & $.970 * *$ & .911 & & & & \\
\hline 3. PsyCap T3 & 4.87 & .445 & $.974 * *$ & $.996^{* *}$ & .905 & & & \\
\hline 4. Goal Achievement T1 & 4.88 & .584 & $.214^{*}$ & .173 & .176 & NA & & \\
\hline 5. Goal Achievement T2 & 4.92 & .542 & $.231 *$ & $.189 *$ & $.193^{*}$ & $.947^{* *}$ & NA & \\
\hline 6. Goal Achievement T3 & 5.06 & .510 & .139 & .107 & .116 & $.636^{* *}$ & $.710^{* *}$ & NA \\
\hline \multicolumn{9}{|c|}{ Study $2(N=101)$} \\
\hline 1. PsyCap T1 & 4.67 & .477 & .885 & & & & & \\
\hline 2. PsyCap T2 & 4.92 & .505 & $.961 * *$ & .931 & & & & \\
\hline 3. PsyCap T3 & 4.90 & .497 & $.965^{* *}$ & $.997^{* *}$ & .926 & & & \\
\hline 4. Goal Achievement T1 & 4.89 & .598 & -.031 & -.013 & -.016 & NA & & \\
\hline 5. Goal Achievement T2 & 4.95 & .572 & .013 & .022 & .018 & $.831^{* *}$ & NA & \\
\hline 6. Goal Achievement T3 & 5.08 & .483 & .091 & .114 & .139 & $.410^{* *}$ & $.484^{* *}$ & NA \\
\hline
\end{tabular}


$[\mathrm{F}(1,108)=.454, \mathrm{p}=.502]$, tenure $[\mathrm{F}(1,108)=.266, \mathrm{p}=.607]$ education $[\mathrm{F}$ $(1,94)=1.245, \mathrm{p}=.267]$, gender $\left[\mathrm{X}^{2}(1)=1.782, \mathrm{p}=.235\right]$, and race (minority vs. nonminority) $\left[\mathrm{X}^{2}(1)=.151, \mathrm{p}=.708\right]$. Thus, pre-intervention group equivalence is supported.

\subsection{Intervention effectiveness}

Because each study included a between-subjects variable (PCI: face-to-face vs. online in Study 1, online vs. micro-learning in Study 2) and a within-subjects variable (repeated measures of PsyCap over time), two-way mixed-design ANOVA was used. This method allowed us to concurrently compare the effectiveness of two PCIs in each study in developing PsyCap and promoting successful goal achievement over time, and to examine the interaction between PCI and time in order to explore potential differences in change patterns.

Fig. 1 Effectiness of face-toface, online, and micro-learning PCIs (a)

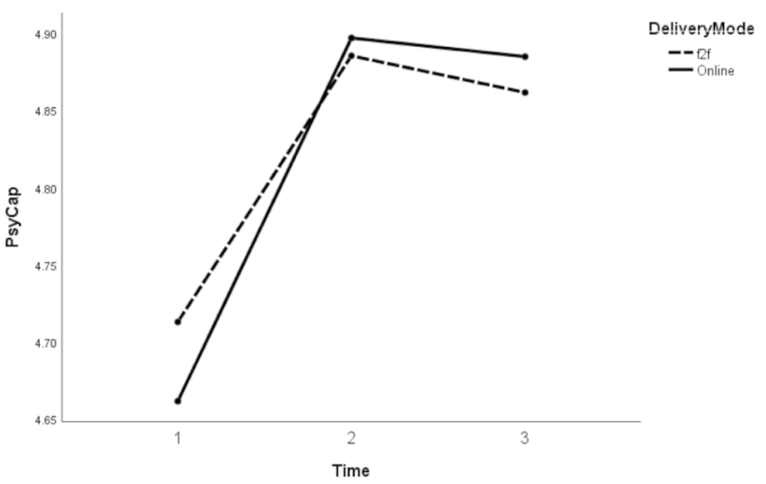

(b)

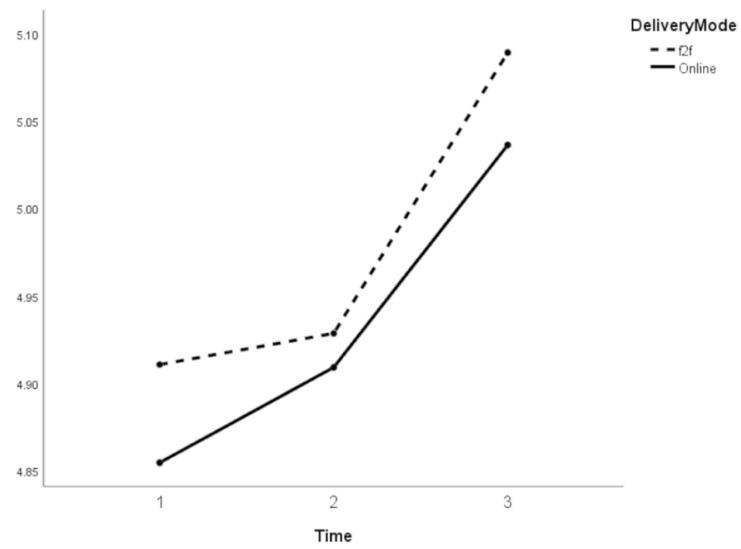


Study 1 results Mixed-Design ANOVA results of Study 1 are shown in Fig. 1.

With respect to PsyCap, the main effect of PCI was not significant [F $(1,109)=.004, p=.949]$. Thus, online and face-to-face PCIs yielded comparable results in terms of PsyCap development. Mauchly's test indicated that the assumption of sphericity has been violated $\left[\mathrm{W}=.306, \mathrm{X}^{2}(2)=128.020, \mathrm{p}=.000\right]$. Therefore, degrees of freedom were corrected using Greehouse-Geisser estimates of sphericity $(\varepsilon=.590)$. As shown in Fig. 1(a), there was a significant main effect for time [F $(1.18,128.662)=302.602, \mathrm{p}=.000]$. Bonferroni corrected post hoc tests and tests of within-subjects contrasts indicated that PsyCap increased significantly immediately after the intervention $[\mathrm{F}(1,109)=322.104, \mathrm{p}=.000]$, and then decreased significantly six weeks later $[\mathrm{F}(1,109)=21.408, \mathrm{p}=.000]$. A quadratic contrast was also supported $[\mathrm{F}(1,109)=274.005, \mathrm{p}=.000]$. This reversal is consistent with the statelike nature of PsyCap. However, PsyCap six weeks after the intervention was still significantly higher than pre-intervention PsyCap $(\mathrm{p}=.000)$. Furthermore, there was a significant interaction between time and PCI $[\mathrm{F}(1.18,128.662)=9.556, \mathrm{p}=.001]$. Specifically, the online group experienced a steeper increase in PsyCap than the face-to-face group immediately after the intervention $[\mathrm{F}(1,109)=7.669, \mathrm{p}=.007]$, but a comparable reversal six weeks later $[\mathrm{F}(1,109)=2.265, \mathrm{p}=.135]$, as shown in Fig. 1(a).

With respect to successful goal achievement, again the main effect of PCI (online vs. face-to-face) was not significant $[F(1,109)=.201, p=.655]$, indicating both PCIs yielded comparable results. Again, Mauchly's test indicated that the assumption of sphericity has been violated $\left[\mathrm{W}=.372, \mathrm{X}^{2}(2)=106.674, \mathrm{p}=.000\right]$. Therefore, degrees of freedom were corrected using Greehouse-Geisser estimates of sphericity $(\varepsilon=.614)$. As shown in Fig. $1(b)$, there was a significant main effect for time $[\mathrm{F}(1.229,133.942)=14.376, \mathrm{p}=.000]$. Bonferroni corrected post hoc tests indicated that successful goal achievement did not change significantly immediately after the intervention $(\mathrm{p}=.132)$, but did increase significantly six weeks later $(\mathrm{p}=.000)$. This delayed change supports PsyCap development as the driving force toward successful goal achievement. PsyCap increased immediately after the intervention, then successful goal achievement increased six weeks later. On the other hand, tests of within-subjects contrasts indicated that successful goal achievement significantly increased, both immediately after the intervention $[\mathrm{F}(1,109)=4.152, \mathrm{p}=.044]$ and six weeks later $[\mathrm{F}(1,109)=14.202, \mathrm{p}=.000]$, although the immediate change was substantially smaller than the long term change. A quadratic contrast was also supported $[\mathrm{F}(1,109)=7.571, \mathrm{p}=.007]$. The interaction between time and PCI was not significant $[\mathrm{F}(1.229,133.942)=.163, \mathrm{p}=.739]$, indicating that both groups experienced a similar pattern of successful goal achievement over time, as shown in Fig. 1(b).

Study 2 results Mixed-Design ANOVA results of Study 2 are shown in Fig. 2. The results were remarkably similar to Study 1 .

With respect to PsyCap, the main effect of PCI was not significant [F $(1,99)=2.033, p=.157]$. Thus, online and micro-learning yielded comparable results in terms of PsyCap development. Mauchly's test indicated that the assumption of sphericity has been violated $\left[\mathrm{W}=.270, \mathrm{X}^{2}(2)=128.138, \mathrm{p}=.000\right]$. Therefore, 
Fig. 2 Convergent parallel mixed method design (Creswell, 2013) (a)

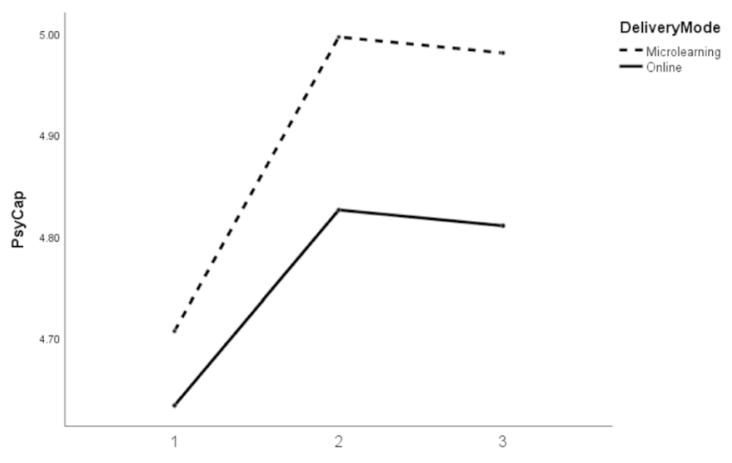

(b)

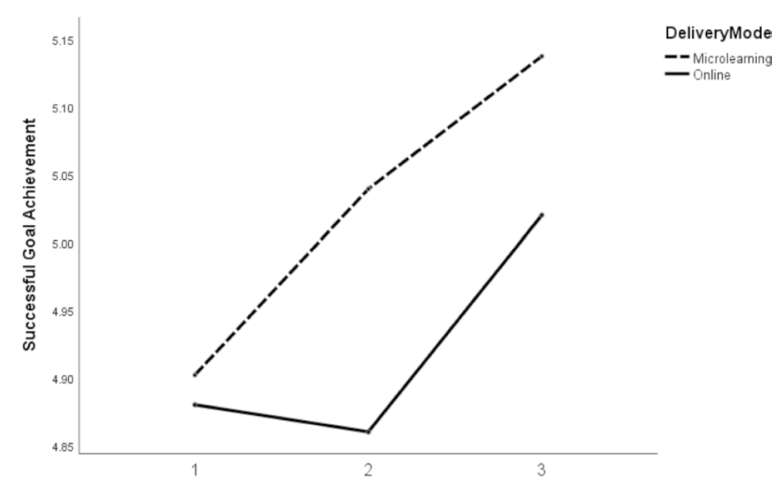

degrees of freedom were corrected using Greehouse-Geisser estimates of sphericity $(\varepsilon=.578)$. As shown in Fig. 2(a), there was a significant main effect for time $[\mathrm{F}(1.156,114.483)=323.059, \mathrm{p}=.000]$. Similar to Study 1, Bonferroni corrected post hoc tests and tests of within-subjects contrasts indicated that PsyCap increased significantly immediately after the intervention $[\mathrm{F}(1,99)=337.329, \mathrm{p}=.000]$, and then decreased significantly six weeks later $[\mathrm{F}(1,99)=14.038, \mathrm{p}=.000]$. A quadratic contrast was also supported $[\mathrm{F}(1,99)=285.027, \mathrm{p}=.000]$. Again, PsyCap six weeks after the intervention was still significantly higher than pre-intervention PsyCap $(\mathrm{p}=.000)$. Furthermore, there was a significant interaction between time and PCI $[\mathrm{F}(1.156,114.483)=13.976, \mathrm{p}=.000]$. Specifically, the micro-learning group experienced a steeper increase in PsyCap than the online group immediately after the intervention $[\mathrm{F}(1,99)=13.720, \mathrm{p}=.000]$, but a comparable reversal six weeks later $[F(1,99)=0.000, p=.992]$, as shown in Fig. 2(a). A quadratic contrast was also supported for this interaction $[\mathrm{F}(1,99)=10.241, \mathrm{p}=.002]$. 
With respect to successful goal achievement, again the main effect of PCI (online vs. micro-learning) was not significant $[\mathrm{F}(1,99)=1.288, \mathrm{p}=.259]$, indicating both PCIs yielded comparable results. Again, Mauchly's test indicated that the assumption of sphericity has been violated $\left[\mathrm{W}=.666, \mathrm{X}^{2}(2)=39.896, \mathrm{p}=.000\right]$. Therefore, degrees of freedom were corrected using Greehouse-Geisser estimates of sphericity $(\varepsilon=.749)$. As shown in Fig. 2(b), there was a significant main effect for time [F $(1.499,148.379)=7.328, \mathrm{p}=.003]$. Bonferroni corrected post hoc tests and tests of within-subjects contrasts indicated that successful goal achievement only marginally increased immediately after the intervention $[\mathrm{F}(1,99)=3.119, \mathrm{p}=.080]$, but did increase significantly six weeks later $[\mathrm{F}(1,99)=5.694, \mathrm{p}=.019]$. The interaction between time and PCI was not significant $[\mathrm{F}(1.499,148.379)=1.247, \mathrm{p}=.283]$. However, upon examination of the within-subjects contrasts, and as shown in Fig. 2(b), the two groups experienced different patterns of successful goal achievement. Whereas the micro-learning group experienced a nearly steady increase in successful goal achievement, the online group experienced a slight decrease immediately after the intervention, followed by a comparable increase six weeks later. Thus, there was a significant difference between the two PCIs in their change in successful goal achievement before and immediately after the intervention $[\mathrm{F}$ $(1,99)=5.609, \mathrm{p}=.020]$.

\subsection{Replicability}

The two studies provided an opportunity for examining replicability of the results. Specifically, we compared the online groups from both studies to examine the stability of the findings across samples. Examination of pre-intervention equivalence yielded no significant differences between the two online groups. Mixeddesign ANOVA yielded a significant main effect for time only, but not for group or group*time interaction. Thus, the results of the intervention were replicated with remarkable consistency across the two online groups in the two studies.

\section{Discussion}

Despite common suspicions regarding the efficacy of online learning compared to face-to-face learning, consistent with Russell's (1999) No Significant Difference, this study shows that these two approaches yield comparable results in the context of PsyCap development. Specifically, the effects of a face-to-face and an online PCI on PsyCap and successful goal achievement were similar. Moreover, a third approach, micro-learning, where content is disseminated in smaller units over a longer period of time, was examined in comparison with online learning. Again, overall, the micro-learning and online PCI appear to yield comparable results. Overall, there was remarkable consistency across the three PCIs and the two studies reported.

However, there are also some subtle but important differences to be noted. Although the overall results are comparable (immediate increase in PsyCap followed 
by reversal; delayed increase in successful goal achievement), it appears that microlearning yields the steepest immediate post-intervention results, both in PsyCap development and in successful goal achievement. With respect to successful goal achievement, the delayed results in the face-to-face and online PCIs are expected, because the face-to-face and online PCIs were administered in one session. Thus, participants did not have any opportunity to improve their goal achievement efforts between the first two measurements (immediately before and immediately after PCI completion). In contrast, the micro-learning PCI was administered over a six-week period. Thus, participants had time to capitalize on earlier modules to improve their goal achievement in the interim. On the other hand, the steeper increase in PsyCap immediately after the micro-learning PCI provides evidence that administering the same content in shorter modules over a longer time period may be a more effective learning approach.

\subsection{Strengths and limitations}

This study provides encouraging new evidence for the efficacy of virtual learning, both when content is delivered in one sitting or over time (micro-learning). Moreover, it tests this notion in the context of positive psychology and PsyCap, which adds to the body of knowledge in these emerging fields of study. Evidence is emerging for the efficacy of positive interventions in general (Bolier et al., 2013), and particularly online (Baños et al., 2017). However, this is the first study that compares face-toface, online, and micro-learning in general, and specifically in the context of positive psychology interventions or PCIs.

Some of the notable strengths of this study include being administered in a real organizational setting, as well as the random assignment of the participants to the interventions. The equivalence of the groups on demographics and pre-intervention variables has also been established. Sample sizes were adequate, and the groups were roughly equal in size. Another strength is the replicability of the results with remarkable consistency over two studies.

Limitations of the study include inability to administer and compare the three PCIs side-by-side in one study due to time and logistics. However, many organizations have had to abruptly switch to virtual learning due to COVID-19. Thus, the ability to include a face-to-face PCI in this study was a notable advantage, even though it could only be included in Study 1. Furthermore, objective performance outcomes could not be used in this study. Instead, a one-item self-reported proxy was used to measure successful goal achievement. However, this single item was consistent with the approach being used in the organization in performance appraisal settings, making it a good fit in this context. Finally, the samples in this study came from a single organization, which represents a challenge to the external validity and generalizability of the findings. 


\subsection{Implications for future research}

The state-like nature of PsyCap (Luthans \& Youssef, 2007), along with its association with employee performance and wellbeing (Avey et al., 2011), makes the development of effective PsyCap interventions a pertinent area for future research. However, comparative studies to assess the efficacy of various PsyCap development approaches are lacking. Our findings show no significant differences between face-to-face, online, and micro-learning PCIs. Future research may consider other approaches such as flipped classrooms (Tucker, 2012), gamification (Johnson et al., 2016), and coaching (Passmore \& Oades, 2014; Peláez et al., 2019). Given the benefits of positive interventions in general (add references), and particularly PCIs (add references that have work or non-work DVs), it is important to explore various approaches to PsyCap development, as well as the contextual and boundary conditions that may render some approaches more effective than others. Future research should also utilize performance measures from multiple sources, including supervisory, peer, and self-ratings, as well as objective performance outcomes, to assess the impact of PCIs more comprehensively. Finally, follow up studies are encouraged to take multi-organizational, multi-industry, and/or multi-cultural approaches to expand external validity and uncover potential unique differences and boundary conditions that may render one approach more effective in some contexts than others.

\subsection{Implications for practice}

Passmore and Oades (2014) posit that a limitation in positive psychology is the dominance of theory over practical solutions. This study explores practical approaches to PsyCap development through various delivery modes. Results showed no significant differences between the three delivery modes examined, namely face-to-face, online, and micro-learning. Practitioners should be particularly interested in these findings given the growing volatility and complexity of the current business environment. Bennett and Lemoine (2014) define complexity as a situation with many interconnected parts, and volatility as an unexpected or unstable challenge with no known duration. Using tools and resources like remote learning applications and other technologies to develop PsyCap will be vital in the emerging "fourth industrial revolution" (Broad \& Luthans, 2020). The business world is increasingly Volatile, Uncertain, Complex, and Ambiguous (VUCA), and this trend has only been accelerated by COVID-19 (Broad \& Luthans, 2020). Although there already was a slow and steady move towards virtual settings, COVID-19 and multiple government enforced lockdowns forced millions to become remote works overnight. It is currently unknown if virtual work will persist, but it is likely as organizations and workers become more accustomed to these changes.

It is also worth noting that in this environment, there is an immense need for positivity in order to promote mental health and overcome the harmful side effects of isolation and rapid change. Simultaneously, there are unprecedented opportunities to capitalize on technology and deliver evidence-based positive interventions to all types of audiences to promote wellbeing and performance. This study shows that 
practitioners can use technology to develop PsyCap without any fear of compromising the outcome.

There are situations where face-to-face development makes sense. These can include workforces with limited access to technology, or organizations that wish to monitor participation. On the other hand, online learning offers the flexibility for employees to learn anywhere they have access, while offering the same structure and schedule as a face-to-face intervention. Micro-learning offers the same benefits as online learning with the additional benefit of spacing the material out in smaller modules. This can be less intrusive for some employees who cannot take long periods of time away from their daily activities. On the other hand, micro-learning also takes a longer timespan to deliver the same content. Thus, utilization of micro-learning should depend on (a) the available time to disseminate the training, and (b) the urgency of beginning to realize the benefits of the training. Thus, based on the results of this study, practitioners are encouraged to utilize the type of learning that fits the available resources and preferences of their organizations, without worrying about compromising the results.

\section{Conclusion}

Online and micro-learning PCIs delivered via mobile applications are at least as effective as or can be more advantageous than face-to-face PCIs. These results support utilizing the approach that fits the available resources and preferences of the organization and employees, without fear of compromising the results. Anecdotal arguments in support of the superiority of face-to-face learning have been repeatedly refuted in the literature, and this study adds to this evidence by showing that in the context of PsyCap development, face-to-face, online, and micro-learning PCIs are comparable in their effectiveness despite some subtle differences.

Availability of data and material The datasets generated during and/or analyzed during the current study are available from the corresponding author on reasonable request.

Funding This research received no specific grant from any funding agency, commercial or not-for-profit sectors.

\section{Declarations}

Conflict of interest On behalf of all authors, the corresponding author states that there is no conflict of interest.

Ethics approval Data for this study was collected in the normal course of business, as part of the organization's ongoing commitment to, investment in, and assessment of human resource development initiatives. All procedures were in accordance with the ethical standards of the 1964 Helsinki Declaration and its later amendments or comparable ethical standards. The study was approved by the HR Council of the organization, which oversees all company-wide HR initiatives.

Consent to participate Informed consent was obtained from all individual participants included in the study. 


\section{References}

Agah, T. K., \& Ayse, A. (2011). Differences between m-learning (mobile learning) and e-learning, basic terminology and usage of m-learning in education. Third World Conference on Educational Sciences Procedia, 15, 1925-1930.

Avey, J. B., Luthans, F., \& Jensen, S. M. (2009). Psychological capital: A positive resource for combating employee stress and turnover. Human Resource Management, 48, 677-693.

Avey, J. B., Luthans, F., \& Youssef, C. M. (2010a). The additive value of positive psychological capital in predicting work attitudes and behaviors. Journal of Management, 36, 430-452.

Avey, J. B., Luthans, F., Smith, R. M., \& Palmer, N. F. (2010b). Impact of positive psychological capital on employee well-being over time. Journal of Occupational Health Psychology, 15, 17-28.

Avey, J. B., Reichard, R. J., Luthans, F., \& Mhatre, K. H. (2011). Meta-analysis of the impact of positive psychological capital on employee attitudes, behaviors, and performance. Human Resource Development Quarterly, 22, 127-152.

Bandura, A. (1997). Self-efficacy: The exercise of control. W. H. Freeman \& Co.

Bandura, A. (1998). Personal and collective efficacy in human adaptation and change. In J. G. Adair, D. Belander, \& K. L. Dion (Eds), Advances in psychological science: Vol. 1 Personal, social and cultural aspects (pp. 51-71). Hove, UK: Psychology Press.

Bandura, A. (2001). Social cognitive theory: An agentic perspective. Annual Review of Psychology, 52, $1-26$.

Baños, R. M., Etchemendy, E., Farfallini, L., García-Palacios, A., Quero, S., \& Botella, C. (2014). EARTH of well-being system: A pilot study of an information and communication technologybased positive psychology intervention. The Journal of Positive Psychology, 9(6), 482-488.

Baños, R. M., Etchemendy, E., Mira, A., Riva, G., Gaggioli, A., \& Botella, C. (2017). Online positive interventions to promote well-being and resilience in the adolescent population: A narrative review. Frontiers in Psychiatry, 8, 10.

Barak, A., Hen, L., Boniel-Nissim, M., \& Shapira, N. A. (2008). A comprehensive review and a metaanalysis of the effectiveness of internet-based psychotherapeutic interventions. Journal of Technology in Human Services, 26, 109-160.

Bennett, N., \& Lemoine, G. J. (2014). What VUCA really means for you. Harvard Business Review, 92(1/2), 27-27.

Bolier, L., Haverman, M., Westerhof, G. J., Riper, H., Smit, F., \& Bohlmeijer, E. (2013). Positive psychology interventions: A meta-analysis of randomized controlled studies. BMC Public Health, 13, $1-20$.

Broad, J. D., \& Luthans, F. (2020). Positive resources for psychiatry in the fourth industrial revolution: Building patient and family focused psychological capital (PsyCap). International Review of Psychiatry, 32, 542-554.

Bruck, P. A., Motiwalla, L., \& Foerster, F. (2012). Mobile learning with micro-content: A framework and evaluation. Bled e Conference, 25, 527-543.

Bryant, F. B., \& Cvengros, J. A. (2004). Distinguishing hope and optimism: Two sides of a coin, or two separate coins? Journal of Social and Clinical Psychology, 23, 273-302.

Buchanan, G. M., \& Seligman, M. E. P. (1995). Afterword: The future of the field. In G. M. Buchanan \& M. E. P. Seligman (Eds.), Explanatory style (pp. 247-252). Lawrence Erlbaum Associates.

Buchem, I., \& Hamelmann, H. (2010). Microlearning: A strategy for ongoing professional development. eLearning Papers, 21(7), 1-15.

Cameron, K. S., Dutton, J. E., \& Quinn, R. E. (2003). Foundations of positive organizational scholarship. In K. S. Cameron, J. E. Dutton, \& R. E. Quinn (Eds.), Positive organizational scholarship (pp. 3-13). Berrett-Koehler.

Carifio, J., \& Rhodes, L. (2002). Construct validities and the empirical relationships between optimism, hope, self-efficacy, and locus of control. Work, 19(2), 125-136.

Carlbring, P., Andersson, G., Cuijpers, P., Riper, H., \& Hedman-Lagerlöf, E. (2018). Internet-based vs. face-to-face cognitive behavior therapy for psychiatric and somatic disorders: An updated systematic review and meta-analysis. Cognitive Behaviour Therapy, 47(1), 1-18.

Carter, J. W., \& Youssef-Morgan, C. M. (2019). The positive psychology of mentoring: A longitudinal analysis of psychological capital development and performance in a formal mentoring program. Human Resource Development Quarterly, 30(3), 383-405. 
Cepeda, N. J., Pashler, H., Vul, E., Wixted, J. T., \& Rohrer, D. (2006). Distributed practice in verbal recall tasks: A review and quantitative synthesis. Psychological Bulletin, 132, 354-380.

Cole, M., Torgerson, C. (2017). Highlights from ATD's new micro-learning research report. Retrieved from http://webcasts.td.org/webinar/2266.

Corbu, A., Peláez Zuberbühler, M. J., \& Salanova, M. (2021). Positive psychology micro-coaching intervention: Effects on psychological capital and goal-related self-efficacy. Frontiers in Psychology, 12,315 .

Cowan, N. (2001). The magical number 4 in short-term memory: A reconsideration of mental storage capacity. Behavioral and Brain Sciences, 24(1), 87-114.

Davis, J., Crabb, S., Rogers, E., Zamora, J., \& Khan, K. (2008). Computer-based teaching is as good as face to face lecture-based teaching of evidence based medicine: a randomized controlled trial. Medical Teacher, 30, 302-307.

Dello Russo, S., \& Stoykova, P. (2015). Psychological capital intervention (PCI): A replication and extension. Human Resource Development Quarterly, 26, 329-347.

Demerouti, E., Erik, V. E., Snelder, M., \& Wild, U. (2011). Assessing the effects of a "personal effectiveness" training on psychological capital, assertiveness and self-awareness using self-other agreement. Career Development International, 16, 60-81.

Donovan, J. J., \& Radosevich, D. J. (1999). A meta-analytic review of the distribution of practice effect: Now you see it, now you don't. Journal of Applied Psychology, 84, 795-805.

Ebbinghaus, H. (1964). Memory: A contribution to experimental psychology. Dover.

Ertosun, Ö. G., Erdil, O., Deniz, N., \& Alpkan, L. (2015). Positive psychological capital development: A field study by the Solomon four group design. International Business Research, 8, 102.

Francescato, D., Porcelli, R., Mebane, M., Cuddetta, M., Klobas, J., \& Renzi, P. (2006). Evaluation of the efficacy of collaborative learning in face-to-face and computer-supported university contexts. Computers in Human Behavior, 22(2), 163-176.

Gander, F., Proyer, R. T., Ruch, W., \& Wyss, T. (2013). Strength-based positive interventions: Further evidence for their potential in enhancing well-being and alleviating depression. Journal of Happiness Studies, 14(4), 1241-1259.

Gassler, G., Hug, T., \& Glahn, C. (2004). Integrated Micro learning-an outline of the basic method and first results. Interactive Computer Aided Learning, 4, 1-7.

Ghonsooly, B., \& Seyyedrezaie, Z. S. (2014). The comparison of language learning strategies and reading comprehension of Iranian EFL students taking web-based and face-to-face instruction. Theory and Practice in Language Studies, 4(6), 1296.

Goodyear, P. (2006). Technology and the articulation of vocational and academic interests: Reflections on time, space and e-learning. Studies in Continuing Education, 28(2), 83-98.

Greenhalgh, T. (2001). Computer assisted learning in undergraduate medical education. Bmj, 322, 40-44.

Gross, B., Rusin, L., Kiesewetter, J., Zottmann, J. M., Fischer, M. R., Prückner, S., \& Zech, A. (2019). Microlearning for patient safety: Crew resource management training in 15-minutes. PLoS One, 14(3), e0213178.

Janiszewski, C., Noel, H., \& Sawyer, A. G. (2003). A meta-analysis of the spacing effect in verbal learning: Implications for research on advertising repetition and consumer memory. Journal of Consumer Research, 30, 138-149.

Jenkins, H. (2009). Confronting the challenges of participatory culture: Media education for the 21st century. Mit Press.

Johnson, D., Deterding, S., Kuhn, K. A., Staneva, A., Stoyanov, S., \& Hides, L. (2016). Gamification for health and wellbeing: A systematic review of the literature. Internet Interventions, 6, 89-106.

Johnson, S. D., Aragon, S. R., \& Shaik, N. (2000). Comparative analysis of learner satisfaction and learning outcomes in online and face-to-face learning environments. Journal of Interactive Learning Research, 11(1), 29-49.

Kapp, F., Proske, A., Narciss, S., \& Körndle, H. (2015). Distributing vs. blocking learning questions in a web-based learning environment. Journal of Educational Computing Research, 51(4), 397-416.

Kauffeld, S., \& Lehmann-Willenbrock, N. (2010). Sales training: Effects of spaced practice on training transfer. Journal of European Industrial Training, 34(1), 23-37.

Kearns, L. E., Shoaf, J. R., \& Summey, M. B. (2004). Performance and satisfaction of second-degree BSN students in web-based and traditional course delivery environments. Journal of Nursing Education, 43(6), 280-284.

Kornell, N., \& Bjork, R. A. (2008). Learning concepts and categories: Is spacing the "enemy of induction"? Psychological Science, 19(6), 585-592. 
Lam, M. (2009). Effectiveness of web-based courses on technical learning. Journal of Education for Business, 84(6), 323-331.

Landis, R. S., Beal, D. J., \& Tesluk, P. E. (2000). A comparison of approaches to forming composite measures in structural equation models. Organizational Research Methods, 3, 186-207.

Lieberman, M. (2020, September 23). COVID-19 fuels big enrollment increases in virtual schools. Retrieved December 20, 2020 from: https://www.edweek.org/leadership/covid-19-fuels-big-enrol lment-increases-in-virtual-schools/2020/09

Litman, L., \& Davachi, L. (2008). Distributed learning enhances relational memory consolidation. Learning \& Memory, 15, 711-716.

Luthans, B. C., Luthans, K. W., \& Avey, J. B. (2014). Building the leaders of tomorrow: The development of academic psychological capital. Journal of Leadership \& Organizational Studies, 21, 191-199.

Luthans, F. (2002a). Positive organizational behavior: Developing and managing psychological strengths. The Academy of Management Executive, 16, 57-72.

Luthans, F. (2002b). The need for and meaning of positive organizational behavior. Journal of Organizational Behavior, 23, 695-706.

Luthans, F., \& Broad, J. D. (in press). Positive psychological capital to help combat the mental health fallout from the pandemic and VUCA environment. Organizational Dynamics, in press.

Luthans, F., \& Youssef-Morgan, C. M. (2017). Psychological capital: An evidence-based positive approach. Annual Review of Organizational Psychology and Organizational Behavior, 4, 339-366.

Luthans, F., \& Youssef, C. M. (2007). Emerging positive organizational behavior. Journal of Management, 33, 321-349.

Luthans, F., Avey, J. B., \& Patera, J. L. (2008). Experimental analysis of a web-based training intervention to develop positive psychological capital. Academy of Management Learning \& Education, 7, 209-221.

Luthans, F., Avey, J. B., Avolio, B. J., \& Peterson, S. J. (2010). The development and resulting performance impact of positive psychological capital. Human Resource Development Quarterly, 21(1), 41-67.

Luthans, F., Avey, J. B., Avolio, B. J., Norman, S. M., \& Combs, G. M. (2006). Psychological capital development: Toward a micro-intervention. Journal of Organizational Behavior, 27, 387-393.

Luthans, F., Avolio, B. J., Avey, J. B., \& Norman, S. M. (2007). Positive psychological capital: Measurement and relationship with performance and satisfaction. Personnel Psychology, 60, 541-572.

Luthans, F., Youssef-Morgan, C. M., \& Avolio, B. J. (2015). Psychological capital and beyond. Oxford University Press.

Luthans, F., Youssef, C. M., Sweetman, D. S., \& Harms, P. D. (2013). Meeting the leadership challenge of employee well-being through relationship PsyCap and health PsyCap. Journal of Leadership \& Organizational Studies, 20, 118-133.

Magaletta, P. R., \& Oliver, J. M. (1999). The hope construct, will, and ways: Their relations with selfefficacy, optimism, and general well-being. Journal of Clinical Psychology, 55(5), 539-551.

Major, A., \& Calandrino, T. (2018). Beyond chunking: micro-learning secrets for effective online design. FDLA Journal, 3(1), 13.

Maloney, S., Haas, R., Keating, J. L., Molloy, E., Jolly, B., Sims, J., et al. (2012). Breakeven, cost benefit, cost effectiveness, and willingness to pay for web-based versus face-to-face education delivery for health professionals. Journal of Medical Internet Research, 14(2), e47.

Martínez, I. M., Youssef-Morgan, C. M., Chambel, M. J., \& Marques-Pinto, A. (2019). Antecedents of academic performance of university students: Academic engagement and psychological capital resources. Educational Psychology, 39(8), 1047-1067.

Masten, A. S. (2001). Ordinary magic: Resilience processes in development. American Psychologist, 56, 227-238.

Mens, M. G., Scheier, M. F., \& Carver, C. S. (2016). Optimism. In S. J. Lopez, L. M. Edwards, \& S. C. Marques (Eds.), Handbook of positive psychology (3rd ed.). Oxford University Press.

Merisotis, J. P., \& Phipps, R. A. (1999). What's the difference?: Outcomes of distance vs. traditional classroom-based learning. Change: The Magazine of Higher Learning, 31(3), 12-17.

Mitchell, J., Stanimirovic, R., Klein, B., \& Vella-Brodrick, D. (2009). A randomized controlled trial of a self-guided internet intervention promoting well-being. Computers in Human Behavior, 25(3), $749-760$.

Mohammed, G. S., Wakil, K., \& Nawroly, S. S. (2018). The effectiveness of microlearning to improve students' learning ability. International Journal of Educational Research Review, 3(3), 32-38. 
Motiwalla, L., \& Tello, S. (2000). Distance learning on the internet: An exploratory study. The Internet and Higher Education, 2(4), 253-264.

Moulton, C. A. E., Dubrowski, A., MacRae, H., Graham, B., Grober, E., \& Reznick, R. (2006). Teaching surgical skills: What kind of practice makes perfect?: A randomized, controlled trial. Annals of Surgery, 244(3), 400-409.

Passmore, J., \& Oades, L. G. (2014). Positive psychology coaching: A model for coaching practice. The Coaching Psychologist, 10(2), 68-70.

Patterson, B., \& McFadden, C. (2009). Attrition in online and campus degree programs. Online Journal of Distance Learning Administration, 12, 1-8.

Peláez, M. J., Coo, C., \& Salanova, M. (2019). Facilitating work engagement and performance through strengths-based micro-coaching: A controlled trial study. Journal of Happiness Studies, 21, 1265-1284.

Peterson, S. J., Luthans, F., Avolio, B. J., Walumbwa, F. O., \& Zhang, Z. (2011). Psychological capital and employee performance: A latent growth modeling approach. Personnel Psychology, 64, 937-963.

Proyer, R. T., Gander, F., Wellenzohn, S., \& Ruch, W. (2014). Positive psychology interventions in people aged 50-79 years: Long-term effects of placebo-controlled online interventions on well-being and depression. Aging \& Mental Health, 18(8), 997-1005.

Reynolds, J. H., \& Glaser, R. (1964). Effects of repetition and spaced review upon retention of a complex learning task. Journal of Educational Psychology, 55(5), 297.

Robinson, B. (2020). What studies reveal about social distancing and remote working during coronavirus. Forbes, Retrieved June 18, 2020 from https://www.forbes.com/sites/bryanrobinson/2020/04/04/ what-7-studies-show-about-social-distancing-and-remote-working-during-covid-19/\#228a10df75 $7 \mathrm{e}$

Robinson, C. C., \& Hullinger, H. (2008). New benchmarks in higher education: Student engagement in online learning. Journal of Education for Business, 84(2), 101-109.

Russell, T. L. (1999). The no significant difference phenomenon. Office of Instructional Telecommunications, North Carolina State University.

Sampson, N. (2003). Meeting the needs of distance learners. Language Learning \& Technology, 7(3), $103-118$.

Sanders, R. (2006). The" imponderable bloom": Reconsidering the role of technology in education. Innovate: Journal of online Education, 2(6).

Schneider, S. L. (2001). In search of realistic optimism: Meaning, knowledge, and warm fuzziness. American Psychologist, 56(3), 250.

Seligman, M. E. P. (1998). Learned optimism. Simon and Schuster.

Seligman, M. E. P., \& Csikszentmihalyi, M. (2000). Positive psychology. American Psychologist, 55, $5-14$.

Seligman, M. E., Steen, T. A., Park, N., \& Peterson, C. (2005). Positive psychology progress: Empirical validation of interventions. American Psychologist, 60, 410.

Shapira, L. B., \& Mongrain, M. (2010). The benefits of self-compassion and optimism exercises for individuals vulnerable to depression. The Journal of Positive Psychology, 5, 377-389.

Sin, N. L., \& Lyubomirsky, S. (2009). Enhancing well-being and alleviating depressive symptoms with positive psychology interventions: A practice-friendly meta-analysis. Journal of Clinical Psychology, 65, 467-487.

Skalka, J., \& Drlík, M. (2018). Conceptual framework of microlearning-based training mobile application for improving programming skills. In Auer M., Tsiatsos T. (eds) interactive Mobile communication. Technologies and Learning, 725, 213-224.

Smith, S. M., \& Rothkopf, E. Z. (1984). Contextual enrichment and distribution of practice in the classroom. Cognition and Instruction, 1(3), 341-358.

Snyder, C. R. (1994). The psychology of hope: You can get there from here. Free Press.

Snyder, C. R. (2000). The past and possible futures of hope. Journal of Social and Clinical Psychology, 19, 11-28.

Snyder, C. R., Irving, L., \& Anderson, J. (1991). Hope and health: Measuring the will and the ways. In C. R. Snyder \& D. R. Forsyth (Eds.), Handbook of social and clinical psychology: The health perspective (pp. 285-305). Pergamon.

Stajkovic, A. D. (2006). Development of a core confidence-higher order construct. Journal of Applied Psychology, 91, 1208-1224. 
Stajkovic, A. D., \& Luthans, F. (1998). Social cognitive theory and self-efficacy. Organizational Dynamics, 26, 62-74.

Stratman, J., \& Youssef-Morgan, C. M. (2019). Can positivity promote safety? Psychological capital development combats cynicism and unsafe behavior. Safety Science, 116, 13-25.

Stromso, H. I., \& Braten, I. (2010). The role of personal epistemology in the self-regulation of internetbased learning. Metacognition and Learning, 5, 91-111.

Summers, J. J., Waigandt, A., \& Whittaker, T. A. (2005). A comparison of student achievement and satisfaction in an online versus a traditional face-to-face statistics class. Innovative Higher Education, 29(3), 233-250.

Tiger, L. (1979). Optimism: The biology of hope. Simon \& Schuster.

Tugade, M. M., Fredrickson, B. L., \& Feldman-Barrett, L. (2004). Psychological resilience and positive emotional granularity: Examining the benefits of positive emotions on coping and health. Journal of Personality, 72, 1161-1190.

Turner, A. (2020). December 2020 mobile user statistics. Retrieved from https://www.bankmycell.com/ blog/how-many-phones-are-in-the-world

Tucker, B. (2012). The flipped classroom. Education Next, 12, 82-83.

Wakil, K., Abdulfaraj, A., Sadula, A., Tofiq, D., \& Nawzad, L. (2019). Performance of distance learning compared with face to face learning. Journal of Educational Science and Technology (EST), 5(1), $1-8$.

Walumbwa, F. O., Peterson, S. J., Avolio, B. J., \& Hartnell, C. A. (2010). An investigation of the relationships among leader and follower psychological capital, service climate, and job performance. Personnel Psychology, 63, 937-963.

Werkle, M., Schmidt, M., Dikke, D., \& Schwantzer, S. (2015). Case study 4: Technology enhanced workplace learning. In responsive open learning environments (pp. 159-184).

Wong, L. H. (2012). A learner-centric view of mobile seamless learning. British Journal of Educational Technology, 43, 19-23.

Youssef, C. M., \& Luthans, F. (2007). Positive organizational behavior in the workplace: The impact of hope, optimism, and resilience. Journal of Management, 33, 774-800.

Youssef-Morgan, C. M. (2014). Advancing OB research: An illustration using psychological capital. Journal of Leadership \& Organizational Studies, 21, 130-140.

Youtz, A. C. (1941). An experimental evaluation of Jost's laws. Psychological Monographs, 53, i-54.

Zetterqvist, K., Maanmies, J., Ström, L., \& Andersson, G. (2003). Randomized controlled trial of internet-based stress management. Cognitive Behaviour Therapy, 32(3), 151-160.

Publisher's note Springer Nature remains neutral with regard to jurisdictional claims in published maps and institutional affiliations. 